\title{
Estrategias de formación lectora en la universidad: la literatura como ámbito transversal para un aprendizaje integrado de la cultura'
}

\author{
Strategies for Reading Training at the University: \\ Literature as a cross-curricular realm for a Culture Integrated Learning
}

\author{
MARÍA ISABEL MORALES SÁNCHEZ \\ Universidad de Cádiz \\ España \\ isabel.msanchez@uca.es
}

(Recibido: 22-10-2015; aceptado: 28-03-2016)

Resumen. Este artículo reflexiona sobre la imperante necesidad de abordar estrategias y metodologías transversales que potencien la capacitación y competencia lectoras en el ámbito universitario. La propuesta toma como punto de referencia esencial a la literatura, entendiéndola como un instrumento idóneo para sustentar contenidos multidisciplinares. Su eficacia como forma vehicular de la cultura y su sensibilidad hacia los cambios sociales y tecnológicos más recientes, no sólo potencia y multiplica las posibilidades de integración de contenidos bajo su auspicio, sino que la convierten en un medio idóneo para desarrollar el pensamiento crítico y trabajar la competencia lectora en niveles de especialización diversos.

Palabras clave: Lectura; literatura; retórica cultural; nuevas tecnologías.
Abstract. This article reflects on the necessity of addressing strategies and transversal methodologies that promote training and competence reading at University level. The proposal takes literature, as its point of reference, understanding it as an instrument to hold multidisciplinary contents and considering its efficiency as a vehicular form of culture and its sensibility towards most recent social and technologies changes. It not only powers and multiplies the possibilities of integration of content under its auspices, but the elements implied make it an ideal medium for developing critical thinking and to work reading competence at different levels of specialization.

Keywords: Reading; literature; cultural rhetoric; new technologies.

\footnotetext{
${ }^{1}$ Para citar este artículo: Morales Sánchez, María Isabel (2016). Estrategias de formación lectora en la universidad: la literatura como ámbito transversal para un aprendizaje integrado de la cultura. Alabe 13. [www.revistaalabe.com] DOI: $10.15645 /$ Alabe2016.13.2
} 
"El libro más útil es aquél en el que los lectores hacen la mitad del trabajo"

Voltaire

\section{Una reflexión previa}

Quiero comenzar este breve acercamiento recordando un número muy interesante de la Revista de Educación, publicado en 2005, en cuya introducción, la bibliotecaria y documentalista Lidia Ollero Jiménez afirmaba: "Pocas actividades del aprendizaje humano han recibido y reciben tanta atención en la sociedad actual como las correspondientes al dominio y perfeccionamiento de las habilidades de la lectura y la escritura" y, más adelante: "cabe afirmar que la dimensión lectora de una sociedad es un indicador de la calidad de sus instituciones educativas y a la vez de sus valores" ${ }^{2}$. Sin desmentir esto, por supuesto, diez años después podríamos afirmar que pocas necesidades continúan actualmente siendo tan imperantes y urgentes como el fomento y la enseñanza de la lectura y de la escritura, esto es, la capacitación lectoescritora especializada. No sólo porque los resultados del informe PISA de $2012^{3}$ puedan resultar inquietantes - siempre desde la prudencia con la que hay que acercarse a este tipo de estudios, sobre todo cuando incluyen conclusiones generalizadoras que soslayan factores específicos sociales y culturales-, sino porque los problemas derivados de una defectuosa formación lectora no solo dificultan el resto del aprendizaje en cualquier materia, sino que origina una deficiencia en la habilitación que desencadena un proceso imparable de deterioro en los estadios posteriores -en detrimento de los procesos de formación de los demás- en el momento en el que cualquier profesional traslada sus carencias al aprendizaje de otros. En los últimos años esta circunstancia parece haber ido evidenciándose con cada vez mayor

\footnotetext{
${ }^{2}$ Introducción al número extraordinario de la revista que, bajo el título "Sociedad lectora y educación” abordaba diversas perspectiva sobre la lectura. Dicho número está disponible en:

http://www.mecd.gob.es/revista-de-educacion/numeros-revista-educacion/numeros-anteriores/2005/ re2005.html

Obtenido el 4 de octubre de 2015

${ }^{3}$ El marco Pisa 2015 retoma lo establecido en 2009-2012 (PISA-ERA) y pone de manifiesto este carácter indisoluble entre la competencia y los hábitos lectores. Con relación a lo que se denomina lectura digital, la conclusión en 2012 acababa precisamente asimilando un mayor porcentaje de éxito en el medio digital a aquellos usuarios que poseían una mayor competencia lectora. Bajo nuestro punto de vista es necesario retomar el concepto de lectura digital y articular una definición clara, pues como tal lectura no debería ser entendida como la constatación de ciertas habilidades y hábitos con relación al manejo del medio, aunque la destreza en el mismo facilite el acceso a otras esferas del desarrollo intelectual, también necesario. Medio y capacidad de comprensión pueden estar vinculados, incluso, entenderse como indisolubles, pero no aluden al mismo tipo de capacitación.

Con relación a los informes mencionados

http://educalab.es/documents/10180/19987/PISA2015lectura.pdf/94d39cfc-ce6a-4357-bf0465c9e2ab317b, obtenido el 3 de septiembre de 2015

http://www.mecd.gob.es/dctm/ievaluacion/internacional/informe-espanol-pisa-era 2009.pdf?documentId=09 01 e72b80d24b47 obtenido el 3 de septiembre de 2015.
} 
frecuencia hasta detectar, en el ámbito universitario, algunas deficiencias en lectura y escritura básicas, difícilmente solventables a corto plazo, pese a la minuciosidad con la que se han diseñado los itinerarios curriculares. En este sentido, pareciera que la abundancia de competencias específicas y la atomización de los contenidos han ido en detrimento de las básicas y transversales, dadas, en la mayoría de los casos, por superadas en etapas anteriores ${ }^{4}$.

No es objeto de este acercamiento abordar este u otro tipo de limitaciones apreciables actualmente en algunos ámbitos de la docencia universitaria, sino el de articular una reflexión sobre la que sustentar propuestas eficaces dirigidas esencialmente a cubrir carencias muy concretas que se detectan a nivel general y que afectan a una capacitación profesional competente y de calidad ${ }^{5}$. Lejos de incurrir en un pesimismo poco constructivo, entendemos que los docentes tienen en la actualidad un reto que implica la construcción de un entorno de aprendizaje específico de alta especialización, donde se responda a los hitos esenciales de una formación -la universitaria- que resulta crucial, simplemente, porque es la más definitiva de todas: la que lanza al individuo a la sociedad, la que lo pone en medio de la realidad, de esa realidad que le exige ser creativo, original, interesante, versátil y competente, además de pedirle actitudes y aptitudes que tienen que ver con la competitividad intelectual ${ }^{6}$. Creemos que todas estas cualidades son susceptibles de entrenamiento y que, por lo tanto, han de adquirirse atendiendo a niveles progresivos de especialización y, sobre todo, que no son accesibles sin la imprescindible competencia lectoescritora sea cual fuere la opción profesional elegida. Si bien es cierto que durante años se han cuidado especialmente estos aspectos en las primeras fases educativas, también durante años se ha entendido que, finalizadas estas fases, el proceso formativo había acabado y, por lo tanto, los lectores ya estaban capacitados para caminar solos y para completar su autoformación. Nada más lejos de la realidad por cuanto los niveles

\footnotetext{
${ }^{4}$ En el caso de las universidades andaluzas, resulta interesante la revisión de los distintos trabajos realizados desde el Observatorio cultural Atalaya -iniciativa que aglutina a todas las universidades andaluzas- y que viene realizando desde hace años trabajos de campo de distinta índole destinados, entre otros objetivos, a medir las necesidades de los culturales de la comunidad universitaria. También en otras publicaciones hemos hecho referencia a la iniciativa de la Universidad de Cádiz de coordinar análisis dirigidos a calibrar la situación real de la cultura universitaria, más concretamente, al informe de 2012 centrado en los hábitos lectores de los universitarios andaluces y en el que se ve revelado cómo, en general, la lectura se entiende como actividad académica, no de ocio. Es decir, la lectura no forma parte de la cotidianidad, por lo que tampoco hay un interés especial por ella. Tampoco el uso de los dispositivos móviles o electrónicos parece potenciar dicho interés. Una de las conclusiones de dicho informe apuntaba cómo, en el conjunto de relaciones sociales y culturales, la lectura ocupa un porcentaje mínimo, no aparece como una costumbre habitual. Vid. Ruiz Angel, P. "Los jóvenes universitarios andaluces" en Barómetro de usos, hábitos y demandas culturales de los estudiantes de las universidades andaluzas, $2^{\mathrm{a}}$ oleada, 2012: 13-32, pp. 17-20.

http://www.observatorioatalaya.es/uploads/pdf/b4e95e2caabb6f9a1ce26e586c349c83daf3bebb.pdf disponible el 20 de enero de 2016.

${ }^{5}$ No obstante entendemos que sería interesante la vinculación de las iniciativas con estudios de carácter interuniversitarios que evalúen carencias específicas, al objeto de diseñar estrategias transversales - pero específicas- aplicables a contextos de educación superior concretos.

${ }^{6}$ Es evidente que la formación del individuo para integrarse en el mercado laboral no siempre ha de pasar por el estadio universitario, pero, bajo nuestro punto de vista, también lo es que el hecho de pasar por él debe garantizar una formación de alta capacitación. La inserción laboral es una de las vertientes de un prisma complejo dẹl que también forma parte el futuro de la investigación, de la formación especializada y del desarrollo tecnológico y cultural. En este sentido es en el que nos referimos a la universidad como un entorno socialmente relevante.
} 
de aprendizaje han de ser continuos y las fases de profundización -a modo de capas- son tantas como las fases de nuestra maduración personal y profesional. Nuestra propuesta parte, por lo tanto, de que es absolutamente erróneo pensar en un proceso cerrado, puesto que la competencia está ligada a nuestra experiencia y aprendizaje durante toda la vida (en cantidad y calidad) ${ }^{7}$.

En algunas ocasiones hemos planteado cuán espinoso resulta el asunto de la madurez lectora y cómo se confunden el acceso a los medios, o su manejo, con la capacitación ${ }^{8}$. También hemos subrayado cómo la lectura y la escritura son formas de sociabilidad $\mathrm{y}$, por tanto, han de ser entendidas adscritas a un contexto determinado que no siempre es ideal ya que no siempre es el nuestro ni el mismo. Leer y escribir son dos procesos esenciales y vitales, nos identifican-definen ante los demás y nos sitúan con respecto a los demás. Si nos detenemos un segundo a pensar en la fuerza que determinados mensajes adquieren en las redes sociales, nos daremos cuenta de que el impacto reside en la imagen que se transmite mediante el mensaje escrito, no en el individuo que lo emite que puede, por otra parte, ocultar su identidad o crear su avatar. Es la escritura y su interpretación el principal modus operandi. Es obvio, como hemos dicho, que la madurez lectora necesita y está vinculada a una madurez intelectual que no proporcionan automáticamente los medios externos (o no solo estos) y que está ligada bidireccionalmente al pensamiento crítico. Cabría preguntarse entonces, entre otras cuestiones, por qué se establecen sin reservas niveles de lectura en primaria, pero no entendemos necesario su establecimiento en la universidad; por qué no se atiende al hecho de que la composición de textos complejos -entre los que se encuentran los académicos- de tipología diversa (desde la reseña hasta el ensayo que subyace en una tesis por no hablar de los proyectos fin de grado) es una cuestión no sólo de formato, sino también de madurez crítica y profesional. Asimismo, cabría pensar, de antemano, que no siempre los métodos empleados para otros niveles sirven tal cual para el universitario porque ya no se trata de repetir o reforzar sino de avanzar progresivamente en la calidad de la lectura. En este sentido, no debemos olvidar de que estamos hablando de individuos que social y culturalmente están influenciados por contextos muy específicos, que ya no son ni niños ni adolescentes, que no son "cuadernos en blanco", que mantienen una relación con lo que les rodea y una opinión sobre lo que les rodea o que pueden pertenecer a un mundo sobreabundante en recursos y medios o a un mundo carente de la cobertura más básica. A partir de aquí, la cantidad de variables y parámetros a tener en cuenta para proporcionar una atención adecuada que cubra las necesidades reales del aprendizaje para su correcta profesionalización o, al menos, orientación, son innumerables. En términos económicos, podríamos hablar de criterios

\footnotetext{
${ }^{7}$ En este sentido llamamos la atención sobre la importancia de atender la formación lectora como un proceso continuo que debe proseguir los esfuerzos e iniciativas realizadas al respecto en los niveles anteriores.

${ }^{8}$ Un ejemplo en Morales Sánchez, M. I. y Cantos Casenave, M. (2015) "El lector enredado. Lectura y aprendizaje” en Campos Fernández, M., De Lara Ródenas, M. y Pérez Collados, J. M. (eds) Releyendo. Estudios de lectura y cultura, Servicio de Publicaciones de la U. de León-RIUL, pp. 55-78.
} 
de segmentación: geográficos, socioeconómicos, psicológicos, culturales, desde los que medir sus necesidades y conocer su actitud ante su propio proceso formativo. Muchas veces el problema de la inmadurez o de la deficiente capacidad crítica tiene su origen en la superprotección o en la inexperiencia para abordar problemas y decidir (si no no tendría sentido iniciativas como la escuela de padres de Marina ${ }^{9}$ ), de hecho, metodologías como "el aprendizaje basado en problemas" y el basado en proyectos ${ }^{10}$ evidencian ítems que corroboran determinados hábitos sociales y educativos que han redundado en un perfil de alumno pasivo, que repite o memoriza -pero no comprende- que no se arriesga porque no se responsabiliza y que no se siente cómodo en la incertidumbre (recordemos la máxima de Mourin), que no acepta desafíos, que no entiende la lentitud natural del proceso de aprendizaje, en un impulso esto último, por cierto, muy vinculado de nuevo a nuestro modus digital de operar. Trasladado al aula estas cuestiones se materializarán en dificultades operativas concretas para las que se reclama constantemente una guía: comprensión del vocabulario, selección de textos, expresión de ideas complejas tanto en el nivel oral como en el escrito, dificultades para organizar un texto, incluso, para identificar la estructura de otros. De todo ello resultan preguntas -algunas sorprendentestales como: ¿qué debería leer entonces para ser culto?, ¿cuál es la “plantilla” para hacer un comentario?, ¿es necesario leer el texto completo?, ¿qué tengo que hacer con el texto exactamente? ¿y esto...para qué sirve? "yo no estudio letras...para qué voy a leer?" ${ }^{11}$...

La dificultad para asimilar ideas integradas en diferentes textos, la resolución superficial del análisis textual basándose exclusivamente en el resumen de ideas y no en su comentario, la incapacidad para reconocer su estructura, en pocas palabras, las carencias en comprensión lectora -no hablamos si no de esto exactamente- se convierten en un impedimento para la creatividad, para la generación de ideas y su expresión, es decir, para la escritura y la expresión oral, lo que nos lleva a dificultades para emitir juicios críticos y argumentar sólidamente. El aprendizaje guiado -excesivamente guiado- parece haber hecho un daño no contemplado inicialmente, provocando una inseguridad que lleva al impulso de copia y pega porque "me pienso" incapaz de crear de forma original. En efecto, una plantilla que rellenar, delimitada, acotada, exacta y precisa, donde no haya lugar para ambigüedades, ni reflexiones, ni relaciones, ni nada que desarrollar es más cómoda, más rápida y menos comprometida que la equivocación o el riesgo.

\footnotetext{
${ }^{9}$ Disponible en http://universidaddepadres.es/. Entre las bases de este proyecto, las siguientes afirmaciones: "Cuando nuestro hijo actúa por su propia iniciativa e interés, aprende y adquiere capacidades y conocimientos mucho más sólidos que si se intenta inculcarle desde el exterior estos mismos aprendizajes" o "El talento no es innato: es el resultado de la educación”. Bajo mi punto de vista, los docentes como tales hemos adquirido un compromiso para dotar a nuestros alumnos de las herramientas y estrategias para hacerlo en TODOS y a TODOS los niveles, para "entrenarlos" en las destrezas y habilidades que le van a permitir acceder no sólo a la información, sino, a lo que es más importante: al conocimiento.

10 Obtenido el 10 de octubre de 2015 desde http://innovacioneducativa.upm.es/guias/Aprendizaje_basado_en_problemas.pdf, accesible 10/10/2015.

${ }^{11}$ En todos los casos basamos estas afirmaciones en la experiencia docente derivada de nuestra actividad en la Universidad de Cádiz, donde impartimos materias vinculadas al análisis del discurso y a la formación del pensamiento crítico.
} 
Con motivo de un encuentro organizado en Cádiz, Daniel Cassany apuntaba cómo probablemente llegaría el momento en el que hablásemos de la retórica de textos basados en el "corta y pega", probablemente en un sentido positivo y como parte de la expresividad generada en nuestra cultura más actual ${ }^{12}$. En realidad no inventábamos nada, porque esa "realidad" ya existía entonces, como propuesta estética, en las novelas de Agustín Fernández Mayo, donde dan buena muestra de cómo la fragmentación, el collage, las wikis y otras realidades generadas en el mundo de la comunicación actual pueden impregnar la escritura. El problema es si poseemos la suficiente competencia para descubrir estas estrategias, para comprender de dónde y por qué surge esa propuesta estética, por qué surge o, lo que es peor, qué es una propuesta estética. Las experiencias de este tipo llegan a su límite cuando nos enfrentamos a manifestaciones como las que contempla la novedosa pero compleja literatura digital o ciertos tipos de textos vanguardistas, provocando en los lectores un desconcierto más vinculado al desconocimiento que al efecto estético. Esta es una de las razones que llevan a la formulación, ante la experimentación con este tipo de textos, de una gran cantidad de respuestas ambiguas o silencios que evidencian que no se sabe dar una interpretación, ni tampoco evaluar / valorar en el contexto qué repercusión, trascendencia o importancia tiene tal o cual obra, tal o cual movimiento, ni tan siquiera cuando hablamos de la sociedad actual o en nuestra propia experiencia. Si bien es cierto que la valoración estética es más compleja para el lector cuanto más cercana le resulta, también lo es que la llamada "generación digital" no es consciente a veces o no identifica las expresiones culturales que se señalan como propias de su generación (a ello sumamos la dificultad para generaciones anteriores), a pesar de la rapidez e inmediatez con la que puede producirse el acceso a la información. Por lo tanto, los retos a afrontar son difíciles y tediosos, porque nos enfrentamos a la necesidad, en primer lugar, de volver a convencer de que el aprendizaje es algo lento, gradual y progresivo, casi en los mismos términos que los endocrinos intentan hacer campaña contra las dietas fulminantemente milagrosas. En segundo, que, para profesionalizarnos, el individuo interesado debe tener claro en qué consiste dicha profesionalización (su especialización) y ser consciente de cómo su paso por la universidad no le otorga un "salvoconducto" para trabajar, sino un espacio de formación que le proporcionará unos recursos y una capacidad de respuesta ante la realidad, aplicable a contextos y situaciones laborales diversas y, lo que es más importante, una madurez intelectual que, con independencia del trabajo o no, es la propia de una sociedad alfabetizada y desarrollada. En tercero, que el mundo que nos rodea no ha surgido por generación espontánea, ni tampoco ha inventado nada que no esté sustentado - a partir de relaciones de continuidad o de rechazo, para contravenirlo o para confirmarlo- en un pasado cultural, social, ideológico, económico y político que no podemos obviar (resulta curioso por ejemplo, el impacto que suele producir en los jóvenes la obra de Conan Doyle El mundo perdido, cuando se les plantea hasta dónde llega la originalidad de Parque Jurásico de Michael Crichton).

\footnotetext{
12 Cassany, D. "De los textos a la práctica pasando por el proceso", conferencia inédita inserta en el III Seminario estival de la Red Internacional de Universidades lectoras en Cádiz: La carpintería de la escritura. Escribir para comprender y comprender para saber qué escribir. 7,8 y 9 de Julio de 2014.
} 
La formación nos hace por lo tanto competentes, pero también ciudadanos inteligentes capaces de resolver, de afrontar o de crear en cualquier faceta de nuestra experiencia vital. Por ende, la formación lectoescritora está directamente ligada al pensamiento crítico y es esencial, fundamental, condición sine qua non en cualquier carrera universitaria. "Leer en la superficie" impide valorar, profundizar y emitir juicios sólidos, pero también hemos de ser conscientes de que sólo nosotros somos quienes podemos “discernir" "separar" "identificar" lo superfluo de lo esencial. Resulta obvio además que hemos de partir del hecho insoslayable de que hay un cambio de parámetro esencial en nuestra relación con el conocimiento: en otros tiempos, el sabio era quien poseía el saber, entendiendo por tal el conocimiento y la información en la misma proporción de importancia, pues la educación y el acceso a la información eran privilegios de un selecto y escueto porcentaje de la sociedad. El nuevo sabio, el sabio actual, no tiene mérito alguno si sólo tiene información (aunque la ocultación o la omisión siga siendo herramienta habitual en algunos medios), destacándose, esencialmente, por saber gestionar, interpretar, asimilar y aplicar dicha información para, posteriormente, generar otra novedosa, original y trascendente. Este es nuestro reto: establecer las bases de una educación especializada eficaz que forme individuos competentes en la generación y análisis de la información, que sepan construir argumentaciones sólidas, fundadas en fuentes fiables y solventes y que sean a su vez capaces de formar a otros individuos en distintos contextos y situaciones. Leer el mundo que nos rodea significa saber analizarlo, saber seleccionar lo importante y saber construir a partir de nuestra lectura una idea de lo que entendemos por "nuestro mundo" o "nuestra realidad”. Una realidad cada vez más compleja en la que la digitalización, la globalización han venido a complicar si cabe aún más sus aristas y vértices.

En continuidad con la idea anterior, es importante apuntar cómo la tecnología ha facilitado de manera extraordinaria el acceso a la información y el desarrollo de múltiples posibilidades de culturización, pero, al mismo tiempo, cabe subrayar también cómo ha complicado los procesos de preparación y nuestra capacitación. En el caso de la lectura y de la escritura, las competencias que hemos de desarrollar se han extendido más allá del ejercicio intelectual de la comprensión, asimilación o interpretación, evidenciando la necesidad de adquirir un número importante de destrezas que tienen que ver con el funcionamiento de los dispositivos digitales en los que leemos y escribimos. Leer competentemente, es, por lo tanto, mucho más complejo que antes, porque implica poseer un conocimiento de la tecnología utilizada y aceptar que los parámetros de la propia idea de leer han cambiado o están cambiando radicalmente ${ }^{13}$. Esos nuevos parámetros de lectura han dado un vuelco en la relación existente entre autor, lector, texto, edición, además de plantear nuevas necesidades lectoras, esto es: aquello que busca el lector en la lectura también ha cambiado radicalmente.

\footnotetext{
13 “El problema no es si dentro de 100 años se podrán leer libros en papel, sino si para entonces tendrá sentido leer libros en papel” José Antonio Cordón García “Sobre lectura, libros y lectores (digitales)". Obtenido el 1 de marzo desde http://elpais.com/elpais/2016/01/10/opinion/1452441603_739731.html
} 
Por último y volviendo a la valoración de la lectura y de la escritura en tanto ejercicios intelectuales -que es el sentido en el que vamos a desarrollarlo en nuestro breve acercamiento $^{14}$ - estamos convencidos de que resulta esencial establecer como primer paso lo que denominamos "la consciencia de la lectura", es decir, la reflexión en torno a qué es leer y qué hacemos cuando leemos. La razón de semejante afirmación se fundamenta en la idea de que las bases esenciales del proceso lector no son radicalmente diferentes en el contexto digital o con textos digitales, es decir, que, salvando las especificidades del soporte de las que hemos hablado anteriormente, las operaciones elementales permanecen intactas. De nuevo Cassany reflexiona sobre la lectura en el medio digital, en respuesta a la cuestión de la dificultad para comprender el nuevo entorno:

Hay que formular con concreción la pregunta de búsqueda y saber utilizar los motores de búsqueda. Hay que distinguir los resultados, libres de los patrocinados, porque unos aparecen a la izquierda y otros a la derecha. Hay que saber leer la URL, descomponerla y saber analizar los parámetros de la web. ¿Quién lo ha escrito? ¿Es de ahora o de hace años? No se fíen de una web que no aclara su firma. Hay que analizar al autor y su lenguaje porque éste es como una forma de vestir que delata a quien lo usa. ${ }^{15}$

Esta y otras afirmaciones similares nos remiten a una cuestión que, bajo nuestro punto de vista, resulta esencial formular y reformular: ¿hay algo nuevo en estos consejos que no estuviese contemplado -evidentemente referido a otro contexto de escritura y lectura- en la Retórica tradicional desde hace milenios?, en otras palabras, ¿estamos ante discursos que plantean una nueva redefinición de los parámetros comunicativos tradicionales? La cuestión, por lo tanto, de fondo, continúa situándonos en el mismo punto: cómo se realiza una lectura competente de nuevas formas de discurso en las que los parámetros comunicativos, los recursos y estrategias persuasivas o el formato ha cambiado sustancialmente. El problema es que este hecho tan obvio no siempre se tiene presente, se olvida, se difumina y se entiende que el control de la tecnología garantiza la comprensión, que el manejo del ordenador ya es muestra de la madurez lectora, que su sola presencia es muestra de capacitación. Este es el gran caballo de batalla: se ha relegado a un segundo plano el entrenamiento en las competencias lecto-escritoras especializadas, se ha obviado la evidente transversalidad de estas competencias y su papel esencial en la comprensión y asimilación de contenidos específicos. Nuestra posición ante el texto -en la pantalla, en papel, en soporte audiovisual- continúa formulando preguntas que tienen que ver con el quién? a quién? qué cuenta? cómo? desde qué perspectiva? donde? y lo que es aún más importante ¿con qué finalidad o intención?. La diferencia es que esas preguntas las podemos resolver con diferentes niveles y grados de dificultad y también tienen respuestas múltiples según dónde y cómo se nos transmita la información.

\footnotetext{
15 Con motivo de una conferencia en el Auditorio de Vigo, Disponible en Faro de Vigo martes 20 de junio de 2006, en la que se abordan aspectos básicos de la comunicacion digital. Obtenido el 3 de julio de 2015 desde

http://www.upf.edu/pdi/daniel_cassany/_pdf/pre/faro06b.pdf
} 
Por último, la necesidad de recuperar la formación lectoescritora especializada desde los presupuestos expuestos no hace sino responder al propio compromiso exigido por el nuevo modelo educativo establecido. Todos nos encontramos con casos en los que advertimos una tendencia general a la recopilación de datos, entendiendo a veces la investigación como algo cercano a la acumulación de información, cuanta más mejor, sin contrastar fuentes, sin citarlas, sin hacer un análisis del estado de la cuestión. Ese modus operandi no puede cambiar si quien aprende no conoce cuáles son las bases de su aprendizaje, qué pretende conseguir y cómo. En este punto lo relevante no es si la información está o no en la Red, porque la identificación de la información, su selección y su interpretación deben hacerse igualmente. Recordemos además que el contexto de Educación Superior ha venido alterando los roles tradicionales, potenciando y primando ítems muy claros respecto de la relación del alumno con su propia formación:

a) Conciencia del aprendizaje: enseñar a aprender a aprender y aprender

b) el aprendizaje autónomo del estudiante tutorizado

c) el análisis de los resultados de aprendizaje, expresadas en términos de competencias genéricas y específicas.

d) Un modelo coperativo profesor-alumno

e) Una organización del aprendizaje: modularidad, espacios curriculares multi y transdisciplinares, al servicio del proyecto educativo global ${ }^{16}$

Por lo tanto, este modus operandi debe incidir no en prolongar lo anterior, sino en dar un salto cualitativo con respecto a lo anterior a través de la formulación de metodologías adaptadas a niveles profesionales y especializados. Es en ese sentido en el que abordamos el enfoque que proponemos a continuación, un enfoque que tiene en cuenta, por una parte, el nuevo contexto educativo, por otra, el contexto cultural (con atención a lo digital) y por último, las carencias reales detectadas en la experiencia docente (siempre he pensado que enseñar significa ser capaz de hacer llegar el conocimiento a cualquier persona, más aún, a aquellas con dificultades). Lo apasionante de este reto es que podemos articular metodologías nuevas sin menoscabo de las bases esenciales que sustentan la esencia de la docencia y nunca antes los docentes han estado tan preparados para abordar estos problemas como en la actualidad. En el ámbito universitario, además, investigación, docencia y divulgación constituyen tres entornos complementarios que permiten la articulación de estrategias eficaces apoyadas en muchas ocasiones por recursos de vanguardia, sin olvidar algo que puede resultar esencial -y no por una visión idealizada de la profesión, sino práctica- que es la vocación.

16 La bibliografía en este sentido es abundantísima, pero una buena síntesis de lo esencial puede leerse en Fernández March, A. (2006) "Metodologías activas para la formación de competencias” Educatio Siglo XXI, [S.l.], v. 24, dic. Disponible en http://revistas.um.es/educatio/article/view/152/135. Obtenido el 10 de noviembre de 2015. 


\section{Un enfoque y una experiencia de lectura desde las bases de la retórica cultural.}

Tras esta breve incursión sobre la importancia de la lectoescritura, establecemos a continuación nuestra propuesta, convencidos de que difícilmente podremos mejorar algo si repetimos innumerables veces lo que sabemos que falla. Parece lógico pensar que la excesiva atomización ha llevado a obviar una formación transversal universitaria que facilita la asimilación de contenidos "cruzados", correspondientes a un saber genérico que, lejos de ser superficial, continúa siendo especializado ${ }^{17}$. Una correcta formación integrada proporcionará una visión global, una perspectiva lo suficientemente amplia como para ser capaz de valorar manifestaciones concretas en su conjunto, con relación al resto y con respecto a otro tipo de manifestaciones distintas a ella, permitiendo alcanzar -y esta es la idea nuclear que nos mueve- un conocimiento suficiente de la cultura y de sus claves esenciales. En el caso de la literatura, un acercamiento a la misma en tanto constructo discursivo no sólo permite abordar su vinculación con otros discursos artísticos y no artísticos, sino evidenciar algo que forma parte de su propia realidad como entidad cultural: su intencionalidad y funcionalidad social, su intertextualidad con otras series de discursos que por asimilación o contraposición se relacionan con ella. Lo que propongo aquí es una incursión en la esencia del discurso, más concretamente, en aquello que la retórica ha explicado durante siglos como disciplina y, desde ella, retomar de nuevo la esencia del aprendizaje lector desde la literatura, incidiendo en la formación como un "entrenamiento" en la comprensión de discursos interrelacionados desde diversas perspectivas y por diferentes causas. En este caso, esa "preparación intencionada” pretende la identificación, el análisis y la asimilación del discurso literario y de los distintos tipos de discurso recogidos o generados a partir del mismo. Nos situamos pues en el ámbito de la retórica cultural, como método de investigación de la cultura, esta vez, a través del discurso literario y su conexión/contraposición con otros discursos. La base de esta perspectiva de trabajo ha sido descrita claramente por el Dr. Albaladejo Mayordomo:

La conciencia que el productor y el receptor tienen de su uso del lenguaje retórico y del lenguaje literario abre una vía a la idea de que estos lenguajes y la comunicación basada en ellos están dentro de un espacio especial cuyas leyes lingüísticas, comunicativas y culturales son diferentes de las de la vida cotidiana (...)

Por la consideración de los discursos como construcciones culturales, la Retórica, atenta a la evolución de la comunicación, pero también a la conciencia sobre la comunicación y, por supuesto, sobre las construcciones que intervienen en ésta, ve potenciada su dimensión cultural, constituyéndose una Retórica cultural dentro del amplio espacio de la Retórica ${ }^{18}$

17 La bibliografía en este sentido es abundantísima, pero una buena síntesis de lo esencial puede leerse en Fernández March, A. (2006) “Metodologías activas para la formación de competencias” Educatio Siglo XXI, [S.l.], v. 24 , dic. Disponible en http://revistas.um.es/educatio/article/view/152/135. Obtenido el 10 de noviembre de 2015 .

18 Albaladejo Mayordomo, T. (2013) “Retórica cultural, lenguaje retórico y lenguaje literario" en Tonos digital, 25, julio de 2013. Obtenido el 15 de diciembre de 2015 desde:

https://www.um.es/tonosdigital/znum25/secciones/estudios-03-retorica_cultural.htm. 
Atendiendo a esa "conciencia" sobre el proceso comunicativo, partimos, como no podía ser de otra forma, de la indagación en torno a qué sea la literatura, cómo se describe, cuál es su modus operandi y qué finalidad persigue; en segundo de cómo construirla siguiendo el principio esencial de que cada elemento contenido tiene una razón de esa última intención que no es más que persuadir organizando un entramado textual en clave de tejido estético. Este último punto resulta también esencial: los textos ("tejidos") se pueden construir con muchos materiales y de muchas formas, de cómo sea la "trama" dependerá el efecto que ejerce en el lector. Esta imagen nos permite ser conscientes de un hecho obvio: las "texturas" resultantes tienen intención de comunicar y de persuadir y esto no sólo se da en el discurso literario, sino en cualquier tipo de discurso, en una dinámica que nos sitúa en el centro mismo de la ideología, de la cultura y del pensamiento. Por lo tanto, el hombre entreteje ese pensamiento con diferentes hilos y diferentes materiales, de donde resultan todo tipo de manifestaciones orales, escritas, audiovisuales, o digitales, que mantienen nudos o nexos comunes entre sí mismas y diferenciales con relación a los discursos que lo contradicen.

Partimos esencialmente de un principio: resulta muy difícil generar una opinión sobre lo que no se conoce, sobre lo que no se sabe cómo funciona. A partir de esta premisa, convertiremos a los textos literarios en el centro nuclear de cualquier operación que hagamos para abordar la comprensión lectora de distintos tipos de discurso y a distintos niveles. Ellos se convierten en el enlace, en el punto de partida al resto de la información, sea del tipo que sea. Aunque por cuestiones de espacio no podremos desarrollar detalladamente los ejemplos seleccionados, intentaremos dar una idea global del enfoque propuesto. En este sentido, forma parte de nuestra metodología el cumplimiento de tres objetivos esenciales:

-que el alumno conozca cuál es el material, cómo se trabaja y cómo se comporta (en este caso la literatura)

-que sea consciente de lo que pretendemos conseguir, teniendo como objetivos finales fundamentales la mejora de su competencia lectora y la dotación de herramientas para "operar" con los textos.

- despertar en el alumno el interés por la literatura como forma de la cultura conectada con otras formas y enlazada desde la dimensión intertextual con textos de diversa índole y de distintas ramas de conocimiento. La literatura, en definitiva, como manifestación cultural que conecta con todos los ámbitos que determinan el pensamiento de una época, de una sociedad y de un autor.

A estos objetivos esenciales añadimos los siguientes:

- Potenciar la formación lectora

- Priorizar el cuestionar sobre el resolver

- Revalorizar el sentido de descubrir frente al de corroborar

- Descubrir el sentido de la investigación y de la indagación en lo desconocido

- Generar un contexto propicio para la creatividad

- Impulsar el desarrollo del pensamiento crítico 
- Proporcionar herramientas y recursos para "actuar" sobre los textos y "buscar" en ellos respuestas

\subsection{Una experiencia de lectura}

Para materializar estas ideas, proponemos a continuación una serie de textos (aunque no reproduzco todos) ${ }^{19}$ sobre los que iremos indicando qué aspectos analizaremos en cada uno de ellos, así como la función asignada en el desarrollo completo de nuestra experiencia de lectura. En esta enumeración de ejemplos y de ideas, podrá advertirse las diferentes formas de actuar sobre ellos y la intencionalidad que subyace tras esa operación. Las enumeramos para una mejor identificación ${ }^{20}$ :

I. Textos con diferentes registros lingüísticos y tipológicos sobre los que planteamos cuatro cuestiones que están relacionadas con el vocabulario y con la especificidad del lenguaje poético:

a) qué me impide poder comentar este texto? ¿Qué escollos identifico en su comprensión? ¿Qué puedo decir de las palabras o de las imágenes marcadas en negrita?

b) Qué medios, herramientas, instrumentos o fuentes de información conozco. ¿Dónde reside la dificultad para comprender las imágenes, los términos o las expresiones?

c) Identifico la intencionalidad del poema?

d) Qué relevancia tiene la forma en la que se disponen los contenidos? ${ }^{21}$

19 Por cuestiones de espacio indico en ocasiones sólo el título o el tipo de texto a utilizar. Hemos de tener en cuenta que la propuesta forma parte de un programa más amplio y que aquí he seleccionado algunos ejemplos para identificar las operaciones más relevantes. En total el número de actividades para la lectura transversal y progresiva supera la quincena.

${ }^{20}$ Lo que muestro aquí es el planteamiento nuclear sobre el que trabajo, no su desarrollo completo, que forma parte de una programación mucho más extensa que combina explicaciones teóricas y prácticas imposibles de reproducir aquí. Llamo la atención pues sobre el modo de entrelazar textos y preguntas, no sobre la solución o la respuesta a las mismas.

21 Quevedo, F. Poesía varia (1997) edic. de James O. Crosby, Letras hispánicas, 134. Undécima edición. Ambos poemas están asimismo disponibles con sus referencias correspondientes en el portal de poesía española http:// www.poesi.as/. Para Quevedo, obtenido del 1 de marzo de 2014 desde http://www.poesi.as.html ; para Lorca, es interesante oir la versión sonora de Carlos Cano y José Menese, obtenido el 20 de septiembre de 2015 desde http://www.poesi.as/fgldt103.htm 
Quevedo. Al mosquito de la trompetilla

Ministril de las ronchas y picadas, mosquito postillón, mosca barbero hecho me tienes el testuz harnero u deshecha la cara a manotadas.

Trompetilla que toca a bofetadas, que vienes con rejón contra mi cuero, cupido pulga, chinche trompetero que vuelas comezones amoladas ¿Por qué me avisas si picarme quieres? que pues das dolor a los que cantas de casta y condición de potras eres.

\section{LORCA. GACELA DE AMOR DESESPERADO}

La noche no quiere venir

para que tú no vengas,

ni yo pueda ir.

Pero yo iré,

Aunque un sol de alacranes me coma la sien.

Pero tú vendrás

Con la lengua quemada por la lluvia de sal

El día no quiere venir

para que tú no vengas

$\mathrm{Ni}$ yo pueda ir.

Pero yo iré

Entregando a los sapos mi mordido clavel.

Pero tú vendrás

Por las turbias cloacas de la oscuridad.

Ni la noche ni el día quieren venir Para que por ti muera

Y tú mueras por mí.

II. La expresividad poética. La coherencia del texto literario.

Análisis de los tres poemas que Gerardo Diego escribió sobre el Ciprés de Silos para analizar cómo la forma poética crea realidades diferentes a pesar de tomar como punto de partida un mismo elemento (el Ciprés). Poemas "El ciprés de Silos”, "El ciprés de Silos (ausente)" y "Primavera en Silos"

III. Mezcla de discursos de origen diverso que desarrollan la misma idea. Dificultades para comprender propuestas estéticas concretas. Dificultades para entender contexto. El arte y sus planteamientos. La relatividad del concepto de Belleza. Dos preguntas y tres ejercicios:

a) cómo interpretas las siguientes obras?

b) por qué pueden ser consideradas artísticas?

c) Desarrolla algunas ideas sobre la Torre Eiffel como objeto artístico a partir de los textos

d) Busca información histórica sobre la inauguración, la polémica...etc

e) Busca otros discursos cuyo eje central sea este monumento. 

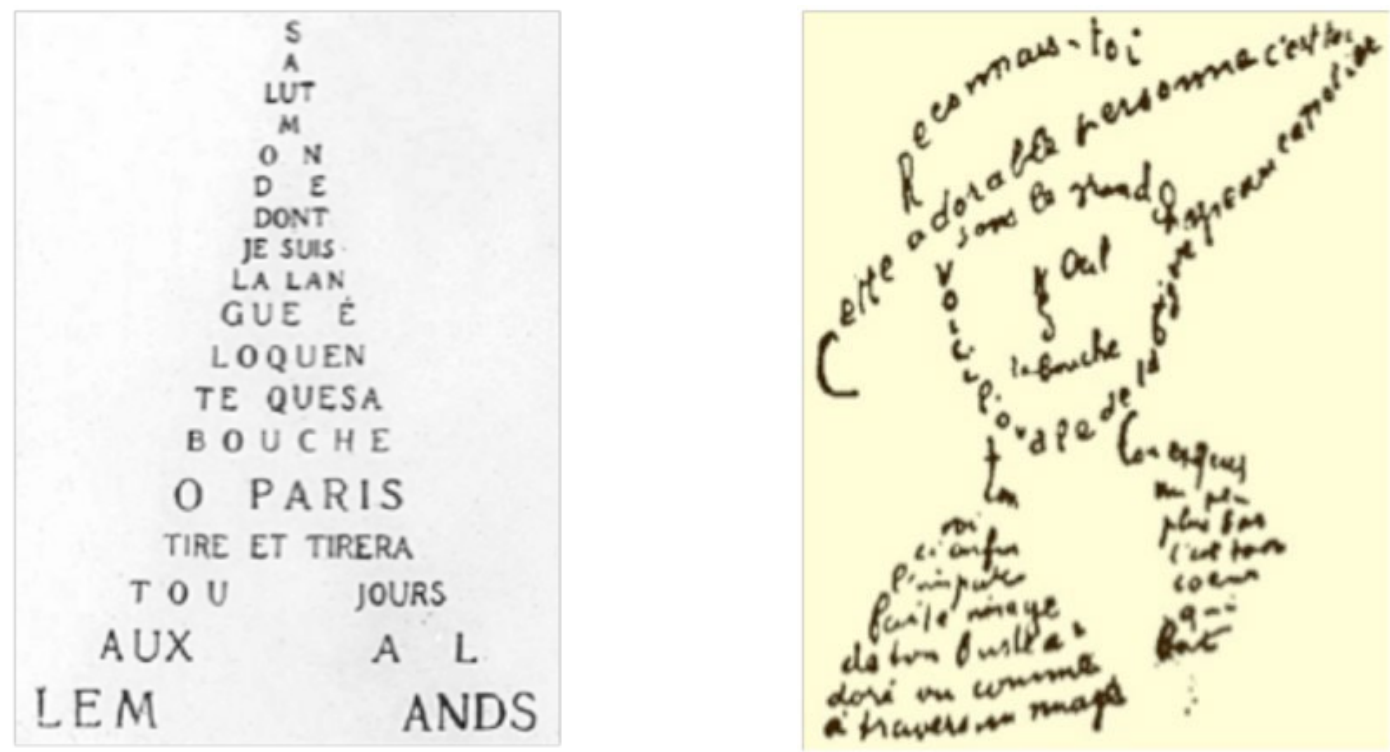

Caligrafias. Guillaum de Apollinaire (1880-1918)

Ambas imágenes disponibles en internet bajo etiqueta de reutilización no comercial

\section{A ello le sumamos un tercer texto a tener en cuenta:}

Escritores, escultores, arquitectos, pintores y aficionados apasionados por la belleza hasta aquí intacta de París, queremos protestar con todas nuestras fuerzas, con toda nuestra indignación, en nombre del gusto francés mal apreciado, en nombre del arte y de la historia franceses amenazados, contra la erección, en pleno corazón de nuestra capital, de la inútil y monstruosa Torre Eiffel. ¿La ciudad de París seguirá por más tiempo asociada a las barrocas y mercantiles imaginaciones de un constructor de máquinas para deshonrarse y afearse irreparablemente? Pues la Torre Eíffel, que ni la misma y comercial América querría, es, no lo duden, la deshonra de París. Todos lo sienten, todos lo dicen, todos se afligen profundamente, y no somos más que un débil eco de la opinión universal, tan legítimamente alarmada. Por último, cuando los extranjeros vengan a visitar nuestra Exposición, exclamarán sorprendidos: “¿Cómo? ¿Éste es el horror que los franceses han encontrado para damos una idea del gusto del que tanto presumen?” Tendrán razón si se burlan de nosotros, porque el París de los góticos sublimes, el París de Puget, de Gerrnain Pilón, de lean Goujon, de Barye, etc., se habrá convertido en el París del Señor Eiffel.» ${ }^{22}$.

22 Carta pública dirigida al Sr. Alphand, comisario de la Exposición. Publicada el periódico Le Temps el 14 de febrero de 1887. Entre los firmantes: Guy de Maupassant, Charles Gounod, Victorien Sardou, Charles Garnier, François Coppée, Sully Prudhomme, Leconte de Lisle, William Bouguereau, Alexandre Dumas (hijo), Ernest Meissonier, Joris-Karl Huysmans y Paul Verlaine. 


\section{Y un cuarto texto a tener en cuenta:}

Maupassant, que desayunaba a menudo en el restaurante de la Torre por ser-decía- el único sitio desde donde no se veía, afirma en La vida errante:

He salido de París y aun de Francia porque acabó por fastidiarme demasiado la torre Eiffel. No solamente se la veía desde cualquier lado, sino que se la encontraba por todas partes, construida de todas las materias conocidas, expuesta en todos los escaparates, pesadilla inevitable y abrumadora. ${ }^{23}$

El salto de los textos creativos a los textos de crítica literaria o a los ensayos, viene a cubrir una experiencia necesaria: la que lleva a ser consciente de que los discursos no surgen de forma aislada, sino que, por el contrario, trascienden la dimensión personal del autor para conectar con una dimensión económica, social, estética y cultural. Tras haber seleccionado textos de autores literarios de diversa índole, ahora la dimensión del escritor es mucho más amplia y conecta con una expresión no solo de cómo entiende el arte sino de qué lugar le otorga en su pensamiento y con relación a lo demás.

IV. Dando un paso más, nos centramos a continuación no en el autor, sino en quién es el crítico y cómo se ejerce la crítica. Para ello tomamos como referencia en esta ocasión a un autor que cambió el modo de estudiar la poesía neoclásica, un autor que marcó una etapa en los estudios dieciochescos, para descubrir qué hizo y cómo. Nos referimos a Russel P. Sebold:

Creo que un requisito indispensable de cualquier trabajo crítico firme, siquiera como hipótesis inicial es el de guardar respecto al concepto que el autor de la obra tenía de ella. Una obra neoclásica tiene que leerse en el contexto histórico y artístico del neoclasicismo y sólo en tal contexto ha de juzgarse y juzgarse con sensibilidad" "Pero por muy iluminativo que sea el contexto artístico y su valor es enorme, suelen resultar todavía más reveladores los apuntes del mismo autor sobre su obra o sobre su visión de la materia ${ }^{24}$

Esto me proporciona la oportunidad de aprender a leer crítica y por ello planteo dos cuestiones:

a) fue verdaderamente un planteamiento innovador la propuesta de Sebold?

b) busca una crítica que plantee un enfoque distinto sobre el tema.

V. Añadimos, para completar esta breve propuesta, el tema de la intertextualidad desde el punto de vista teórico y práctico. Proponemos al alumno que lea la escena de Hammlet donde Ofelia aparece flotando en las aguas.

23 Citamos por la edición de Marbot, 2010.

24 Sebold, R. (1989) El rapto de la mente, Antrhopos, pp. 31-32. 
Hamlet, Acto IV escena VII. Noticia de la muerte de Ofelia

(Entra la Reina)

¿Qué sucede, amada reina?

REINA.- Una desgracia va siempre pisando los talones de otra; tan cerca se suceden. Tu hermana se

ha ahogado Alertes

LAERTES.- ¡Ahogado! Oh! Dónde?

REINA.- Inclinado a orillas de un arroyo, elévase un sauce que refleja su plateado follaje en la ondas

cristalinas. Allí se dirigió, adornada con caprichosas guirnaldas de ranúnculos, ortigas, velloritas yesas largas flores purpúreas a las cuales nuestros licenciosos pastores dan un nombre grosero, pero que nuestras castas doncellas llaman dedos de difuntos (orquídeas). Allí trepaba por el pendiente ramaje para colgar su corona silvestre, cuando una pérfida rama se desgajó y junto con sus agrestes trofeos vino a caer en el gimiente arroyo. A su alrededor se extendieron sus ropas y, como una náyade, la sostuvieron a flote durante un breve rato. Mientras, cantaba estrofas de antiguas tonadas, como inconsciente de su propia desgracia, o como una criatura dotada por la Naturaleza para vivir en el propio elemento. Mas no podía esto prolongarse mucho, y los vestidos, cargados con el peso de su bebida, arrastraron pronto a la infeliz a una muerte cenagosa, en medio de sus dulces cantos ${ }^{25}$

Posteriormente, le pedimos que busque textos de cualquier tipo que reproduzcan la escena y el personaje: el poema de Rimbaud, el cuadro de Millais, el personaje o personajes similares desde el cómic, el manga...etc. A ello le sumamos las definiciones sobre intertextualidad de Genette y Barthes o algunos textos donde se perfilan movimientos específicos ligados, por ejemplo, a la posmodernidad (según el nivel de especialización que queramos alcanzar). Luego, se le pide que elabore un breve tema donde explique las relaciones intertextuales existentes en otros textos de su elección, intentando que sean de distinto tipo.

VI. Para finalizar, un paso más complejo, propondría una incursión en la literatura digital ${ }^{26}$ para intentar comprender su lógica y su intencionalidad como propuesta estética actual.

\footnotetext{
25 Shakespeáre, W. Obras completas, Madrid, Aguilar, 2003, pp.152,153

${ }^{26}$ En los ejemplos tres obras en español del autor Félix Remírez (Bilbao): La hermandad de los escribanos, El generador de relatos y El jardín de los relatos inacabados, todos ellos disponibles en Bliblumliteraria. La emoción de las palabras (blog del autor) http://biblumliteraria.blogspot.com.es/.
} 

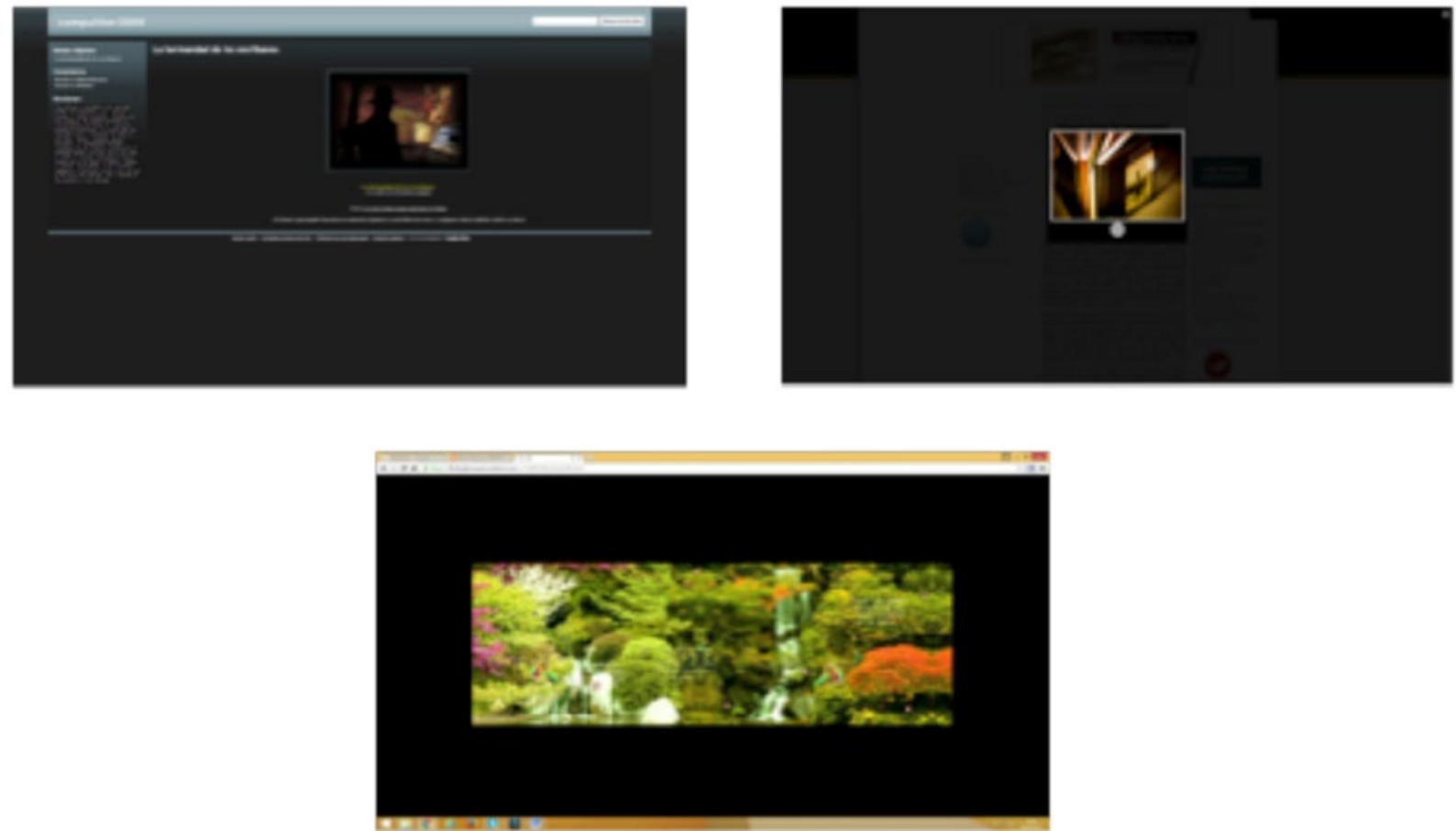

\subsection{Un poco más sobre la teoría que sustenta esta experiencia.}

Convencidos de la eficacia de la transversalidad como método para generar una conciencia crítica capaz de analizar los distintos tipos de discurso, los ejemplos anteriores permiten, entre otros aspectos, la vuelta al proceso de composición, una inversión que me permite relacionar, conectar y enlazar un conjunto de ideas que me han llegado fragmentadas (armar y construir, por lo tanto, una idea, un pensamiento, a partir de varios). Ello permite sin duda dar un giro en la forma de abordar los escollos y las deficiencias demostradas con relación a la competencia lectora y los modos desde los que se acomete la comprensión de los discursos implícitos en todo discurso, pues abre la vía a una lectura -precisamente ahora tan traída y llevada- no lineal. Lo esencial es que, bajo nuestro punto de vista, dicho giro puede ser enormemente facilitado por el enfoque de la retórica cultural, porque, en realidad, esta perspectiva proporciona un ámbito de estudio complejo, donde se tiene en cuenta la producción del discurso como manifestación cultural interrelacionada e interconectada -compartiendo presupuestos con la semiótica de la cultura- y evitando su interpretación aislada. La fragmentación de la información -hecho que marca la comunicación actual- requiere de una estrategia que permita volver a conectar dicha información desde sus conexiones menos volubles y la centralización en la cultura permite establecer una base amplia fácilmente identificable.

Volvemos a reiterar que el eje de nuestra propuesta pivota alrededor de la importancia de la palabra y de su capacidad comunicativa. Hasta qué punto somos conscientes de la trascendencia o de la repercusión que tiene la forma en cómo nos comunicamos o cómo utilizamos el lenguaje....? (o lo que es lo mismo, la escritura) y hasta dónde o con qué intención y fin la utilizan los demás (lectura). Hablar del tejido discursivo de una cultura es una metáfora que identifica la interdiscursividad -con todos los conceptos que 
ello implica- como nudo gordiano que requiere un eficaz e intensivo entrenamiento para su resolución. En efecto, la complejidad de su análisis deriva de la propia complejidad del análisis del pensamiento, de la ideología, de la sociedad y, por ende, de la cultura.

En esto, resulta siempre oportuno recordar al Gorgias del Encomio a Elena

La palabra es un gran soberano que con un cuerpo pequeñísimo y totalmente invisible realiza acciones divinas. Puede, en efecto, hacer cesar el miedo, eliminar el dolor, provocar el gozo, aumentar la compasión. Cómo sucede voy a explicarlo. Es preciso que lo explique para la opinión de los oyentes. Considero, así como lo digo, que cualquier clase de poesía es un discurso con medida; a quien la escucha penetra un escalofrío lleno de terror, una compasión que arranca las lágrimas, una codicia derretida de nostalgia; por efecto de la palabra el alma sufre un sufrimiento peculiar en relación a la suerte y al fracaso de hechos y personas ajenas ${ }^{27}$.

O las ideas expuestas por el neurobiólogo Pierre Magistretti, coautor de un modelo fisiológico para el psicoanálisis, quien afirma que la palabra puede curar como un fármaco ${ }^{28}$.

Volviendo al discurso y a su lógica, son numerosas las voces que recalan en la actualidad en la necesidad de esta recuperación como núcleo del aprendizaje: en palabras del Dr. Hernández Guerrero: "la Retórica es clave en la cultura y en la enseñanza"29, a lo que añadimos que así lo es porque identifica formas de comunicación que nacen de un modo de concebir el mundo. Raramente podremos comprender las repercusiones que el contexto digital tiene en nuestros hábitos si no analizamos qué tipo de discursos y con qué fin genera. Recordemos la idea ya mencionada del profesor Albaladejo y su afirmación de cómo la cultura tiene a su vez una función imprescindible en la Retórica ${ }^{30}$, planteamiento que subyace asimismo en los estudios realizados en la Universidad de Urbino por Stefano Arduini o Mateo Damiani : "nella struttura, nello stile di un testo si riflettono dunque le ideologie e la visione del mondo proprie di un individuo/cultura: in questo senso la retorica testuale generale è cognitiva e culturale" 31 . También, esta vez desde el ámbito de la historia, el profesor de la Universidad de Huelva, José Luis Sánchez Lora, insiste en la trascendencia de la disciplina: "Es necesario integrar el estudio de la Retórica en la historia de la lectura, sencillamente porque ella ha sido, durante más de dos milenios, el código fundamental desde el que se generaba todo texto"32

\footnotetext{
27 Gorgias Encomio de Helena, 11, 8 DK

28 Aconsejamos asimismo Hernández Guerrero, J. Antonio (2010) ¿Curan las palabras?. Manual de comunicación médica y sanitaria, disponible en www. cervantes.virtual.com

29 Hernández Guerrero, J. A y García Tejera, M.C. (2004) El Arte de hablar. Manual de Retórica Práctica y de Oratoria Moderna, Barcelona, Ariel, pp. 59-65

${ }^{30}$ Albaladejo Mayordomo, T. op.cit.

http://www.tonosdigital.com/ojs/index.php/tonos/article/viewFile/974/622

31 Damiani, M. (2010) "La retorica generale testuale in una prospettiva culturale congnitiva” Rhêtorichê. Revista digital de Retórica, $\mathrm{n}^{\mathrm{o}}$ 3, 2010 disponible en http://www.rhetorike.ubi.pt/03/pdf/Rhetorike03-la-retorica.pdf Revista Rhêtorikê. No3. 49-72. Obtenido en noviembre de 2015

32 “Retórica, oralidad y lectura en la Edad Moderna", Cuadernos de Historia Moderna, 2002 I, pp. 65-84.
} 
Particularmente nos gusta insistir en que la escritura es nuestro medio para mostrarnos al mundo y la lectura nuestra forma de penetrar en él. Los textos forman parte de una situación comunicativa que el lector debe comprender, por ello hemos de insistir de nuevo en la importancia de identificar el texto desde varias direcciones que nos lleven al contexto cultural que lo genera. En este sentido podemos afirmar (marco en negrita los términos clave):

- Un texto puede ser influenciado por todo lo que existe con anterioridad o simultaneidad a él, pero no podemos identificar las claves básicas del texto desde una perspectiva posterior. Ello no quiere decir que la cultura no pueda releer y reinterpretar el pasado pero la explicación del mismo se remonta al momento anterior a él. Por lo tanto hemos de discernir entre explicación e interpretación o reinterpretación, ya que corresponden a dos esferas de actuación diferentes sobre los textos. Un ejemplo: podemos analizar la influencia que ejerce Joyce y su modo de emplear el monólogo interior en la escritura contemporánea a él y posterior, pero la explicación del porqué de esta iniciativa creativa no puede estar en lecturas posteriores al momento en el que surge su propuesta. Otro ejemplo, esta vez desde otro ámbito: el geógrafo Pere Sunyer Martín nos explica otras conexiones que propician la aparición de la literatura científica con las corrientes experimentales en el siglo XIX, sin negar la consabida influencia del pensamiento positivista: "Sería injusto adjudicar al auge científico y tecnológico del siglo XIX la aparición de la divulgación científica en la literatura. Es mejor afirmar que es en este siglo cuando nace una verdadera necesidad de vulgarizar todos los conocimientos amasados por la ciencia. Necesidad que estaría vinculada con la formación del nuevo hombre del mañana y la sociedad futura" 33 .

- Un texto puede ser interpretado y reinterpretado tantas veces como lecturas tenga. De hecho muchas corrientes estéticas se basan en la relectura de espacios a los que se les añade una nueva perspectiva, enfoque o visión. Puedo poner como ejemplo la interesante propuesta que actualmente realiza la ecocrítica o, en un sentido más clásico, la ya mencionada reivindicación de Sebold en aras de una crítica no sesgada, de la necesidad de una relectura de la poesía del XVIII desde las claves correctas ante la tendencia a explicarla desde la perspectiva de los siglos de oro.

- La influencia del contexto cultural (filosófico, científico, literario, artístico, ideológico) es obvia, cabe decir que los discursos forman parte de la cultura y la conforman por lo que esta afirmación roza la inexactitud. La interacción de discursos provoca la influencia, por ejemplo, de las teorías de Darwin sobre la clasificación en género/ especies, en la clasificación de la historia literaria propuesta por Brunetière.

- Por último, la cultura crea un imaginario que afecta a la construcción de los discursos y esto, en el caso de los discursos artísticos, genera un acervo cultural que aglutina visiones del mundo en las que se produce, interpreta y reinterpreta espacios o territo-

33 Pere Sunver Martin, “Literatura y ciencia en el siglo XIX. Los viajes extraordinarios de Jules Verne”, GEO CRITICA, Cuadernos Críticos de Geografía Humana, no 76, julio de 1988. Versión digitalizada obtenida en octubre de 2015 desde http://www.ub.edu/geocrit/cienbil.htm 
rios. Ello nos lleva a un ámbito no menos apasionante: el que conecta la literatura y los discursos interconectados a ella con la idea de construcción y reconstrucción del paisaje cultural (aunque esto sería otro eslabón más cuyo desarrollo merece un análisis que no procede ahora).

\section{A modo de conclusión}

En definitiva, el análisis interdiscursivo permite la identificación de un discurso determinado (político, histórico, literario, filosófico) como un universo coherente que guarda conexiones de diferente naturaleza con la cultura que lo produce, conformándose en un entramado que se dilata -entre otros- por extensión, por contraposición, por intertextualidad implícita o explícita con otros discursos (vuelvo a la imagen del entramado, del tejido). Las tipologías textuales no son más que formas de construir dicho tejido articulando una gran cantidad de significados que están dentro y fuera del texto.

Sólo una mirada interdisciplinar y un enfoque transversal permiten evidenciar esto. Hasta ahora la metodología seguida se articulaba como un mosaico de disciplinas específicas que el alumno debía interconectar, sin embargo, los resultados son deficientes, porque la excesiva segmentación ha originado no sólo una práctica que destierra dicha transversalidad, sino la idea de que las cosas son así de fragmentadas. Se nos exige una capacidad de adaptación y una versatilidad para lo que no estamos entrenados. En el contexto global se añade además otras dificultades para la comprensión que tiene que ver con la complejidad del contexto comunicativo, para cuyo análisis puede aplicarse asimismo otro concepto generado en los últimos años desde el seno de la Retórica cultural. Hablamos del concepto de Poliacroasis, entendiendo por tal la recepción plural del discurso, ciertamente fructífero para explicar muchas de las características esenciales de discursos digitales.

El triunfo de la interactividad y de la interacción en tiempo real, de la posibilidad de simultanear discursos plurales y multiculturales -hecho que permite la tecnología- es la consecuencia de una forma de comunicación donde impera el protagonismo del lector, receptor, oyente, internauta. Pero ese privilegio tiene un coste: el de la necesidad de una capacitación en la lectura e interpretación de dichos discursos y el de la capacitación en el manejo del medio. Esta condición de recepción plural es la base del funcionamiento de redes, foros, los blogs...etc. El estudio del funcionamiento de diferentes discursos que se simultanean en una realidad determinada es precisamente, para Raul Urbina ${ }^{34}$ el espacio idóneo donde se mueve la retórica cultura, desde la que se explicarían -afirma- la práctica totalidad de los discursos de carácter persuasivo centrados en el receptor.

\footnotetext{
${ }^{34}$ Urbina, R. (2013) “Poliacroasis y argumentación emocional. El discurso publicitario y la retórica cultural” Tonos digital. Revista electrónica de estudios filológicos, $\mathrm{n}^{\circ} 24$. Obtenida el 9 de noviembre de 2015.
} 
Para terminar, estamos absolutamente de acuerdo con José Antonio Caride cuando afirma:

Escribimos y leemos por necesidad, utilizando las diversas formas de ejercitar la lectura en soportes, procedimientos, signos..., cada vez más plurales y abiertos a los cambios tecnológicos y sociales. En cierto modo, la expresión sociedad lectora remite sus señas de identidad a esta circunstancia, poniendo de manifiesto las variadas opciones que tiene la lectoescritura como creación y expresión, palabra y diálogo; todas ellas son exponentes visibles de procesos de información y comunicación cuya creciente complejidad solo puede ser explicada e interpretada en clave social. Una sociedad lectora es, por tanto, una sociedad que lee y escribe reflexionando sobre sí misma, que, al tiempo que activa los múltiples lenguajes que ambas prácticas inducen textual y contextualmente, agranda sus oportunidades de enseñar y aprender, de vivir y convivir. $^{35}$

Todos emitimos discursos y tenemos la necesidad de "leer más allá". Si hay algo que internet y las nuevas tecnologías han originado es la existencia de un marco comunicativo aún más complejo plurilingüe y pluricultural donde la capacidad para comprender al otro se convierte en necesidad imperante. Saber leer, leer entre líneas, leer más allá, en definitiva, desarrollar el pensamiento crítico es ahora lo que va a determinar nuestra capacidad de adaptación y supervivencia. El discurso digital también posee su propia lógica de construcción, su propio código, su propia Retórica o conjunto de procedimientos que aseguran la eficiente comunicación.

Por lo tanto, es necesario articular un marco docente que permita:

- el entrenamiento lector

- el entrenamiento en la identificación de discursos

- el entrenamiento en la identificación de las relaciones que establecen entre ellos

Asimismo hemos de poner las nuevas tecnologías al servicio de la lectura:

- comprender el proceso lector

- insistir en la formación que permite la construcción de discursos críticos

- combinar diversas metodologías que permitan establecer un marco versátil de trabajo con el alumno.

35 Caride, J. A. "Sociedad lectora" en Diccionario digital de nuevas formas de lectura y escritura (DINLE), Universidad de Salamanca. Proyecto de la Red Internacional de Universidades lectoras. Acceso y consulta en http://dinle. usal.es/userlist.php\# 


\section{Bibliografía citada}

- Albaladejo Mayordomo, T. (2013) "Retórica cultural, lenguaje retórico y lenguaje literario" en Tonos digital, 25, julio de 2013. Obtenido el 15 de diciembre de 2015 desde:

https://www.um.es/tonosdigital/znum25/secciones/estudios-03-retorica_cultural.htm.

- AA.VV. Informe Pisa (2015) Obtenido el 3 de septiembre de 2015 desde http://educalab.es/documents/10180/19987/PISA2015lectura.pdf/94d39cfc-ce6a4357-bf04-65c9e2ab317b

- Caride, J. A. "Sociedad lectora" en Diccionario digital de nuevas formas de lectura y escritura (DINLE), Universidad de Salamanca. Proyecto de la Red Internacional de Universidades lectoras. Acceso y consulta en http://dinle.usal.es/userlist.php\#

- Cordón García, José A. “Sobre lectura, libros y lectores (digitales)” Artículo obtenido el 1 de marzo desde http://elpais.com/elpais/2016/01/10/opinion/1452441603_739731.html

- Damiani, M. (2010) “La retorica generale testuale in una prospettiva culturale congnitiva" Rhêtorichê. Revista digital de Retórica, n 3, 2010 disponible en http://www.rhetorike. ubi.pt/03/pdf/Rhetorike03-la-retorica.pdf Revista Rhêtorikê. No3. 49-72. Obtenido en noviembre de 2015

- Fernández March, A. (2006) "Metodologías activas para la formación de competencias" Educatio Siglo XXI, [S.1.], v. 24, dic. Disponible en http://revistas.um.es/educatio/article/view/152/135. Obtenido el 10 de noviembre de 2015.

- Hernández Guerrero, J.A. (2010) ¿Curan las palabras?. Manual de comunicación médica y sanitaria, disponible en http://www.cervantesvirtual.com/nd/ark:/59851/bmcpc3j4. Accesible el 20 de febrero de 2015

- Hernández Guerrero, J. A y García Tejera, M.C. (2004) El Arte de hablar. Manual de Retórica Práctica y de Oratoria Moderna, Barcelona, Ariel, pp. 59-65

- Morales Sánchez, M. I. (ed.) (2010) Dossier de competencias culturales de los Universitarios, Colección Atalaya, no 46. Versión digitalizada disponible en:

http://www.observatorioatalaya.es/es/productosnew/dossier-de-trabajo-competenciasculturales-de-los-universitarios/48

- Morales Sánchez, M. I. Cantos Casenave, M. (2015) “El lector enredado. Lectura y aprendizaje” en Campos Fernández, M., De Lara Ródenas, M. y Pérez Collados, J. M. (eds) Releyendo. Estudios de lectura y cultura, Servicio de Publicaciones de la U. de León-RIUL, pp. 55-78. 
- Ollero Jiménez, L. (2005) “Introducción” en Sociedad lectora y educación, número extraordinario, Obtenido el 4 de octubre de 2015 de

http://www.mecd.gob.es/revista-de-educacion/numeros-revista-educacion/numerosanteriores/2005/re2005.html

- Pere Sunyer Martin, "Literatura y ciencia en el siglo XIX. Los viajes extraordinarios de Jules Verne", GEO CRITICA, Cuadernos Críticos de Geografía Humana, n 76, julio de 1988. Versión digitalizada

- Ruiz Ángel, P. “Los jóvenes universitarios andaluces” en Barómetro de usos, hábitos y demandas culturales de los estudiantes de las universidades andaluzas, $2^{\text {a }}$ oleada, 2012: 1332, pp. 17-20. Ruiz http://www.observatorioatalaya.es/uploads/pdf/b4e95e2caabb6f9a1ce26e586c349c83daf3bebb.pbf disponible el 20 de enero de 2016.

- Sánchez Lora, J. L (2002) “Retórica, oralidad y lectura en la Edad Moderna”, Cuadernos de Historia Moderna, I, pp. 65-84.

- Urbina, R. (2013) "Poliacroasis y argumentación emocional. El discurso publicitario y la retórica cultural” Tonos digital. Revista electrónica de estudios filológicos, $\mathrm{n}^{\circ} 24$. Obtenida el 9 de noviembre de 2015.

\section{Para los textos tomados como ejemplo:}

- Quevedo, F. Poesía varia (1997). edic. de James O. Crosby, Letras hispánicas, 134.

- Lorca, F. (1967). Antología poética (1918-36), Buenos Aires Losada. También disponible en el portal de poesía española http://www.poesi.as/fgldt103.htm-

- Maupassant, G. (2010). La vida errante, Traducción de Elisenda Julibert, Marbot ediciones.

- Sebold, R. (1989). Elrapto de la mente, Barcelona, Antrhopos.

- Shakespeáre, W. Obras completas, Madrid, Aguilar, 2003, pp.152,153

- Remírez, F. Obras digitales La hermandad de los escribanos, El generador de relatos y El jardín de los relatos inacabados, todos ellos disponibles en Bliblumliteraria. La emoción de las palabras (blog del autor) http://biblumliteraria.blogspot.com.es/. 